\title{
Parecoxib Reduces Systemic Inflammation and Acute Lung Injury in Burned Animals with Delayed Fluid Resuscitation
}

\author{
Si Jack Chong,, Yong Chiat Wong, ${ }^{2}$ Jian Wu, ${ }^{2}$ Mui Hong Tan, \\ Jia Lu, ${ }^{2}$ and Shabbir M. Moochhala ${ }^{2}$ \\ ${ }^{1}$ Naval Medical Service, Singapore Armed Forces, Singapore \\ ${ }^{2}$ Combat Protection and Performance Lab, Defence Medical \& Environmental Research Institute, \\ DSO National Laboratories (Kent Ridge), 27 Medical Drive No. 12-01, Singapore 117510 \\ Correspondence should be addressed to Yong Chiat Wong; wyongchi@dso.org.sg
}

Received 24 September 2013; Revised 20 November 2013; Accepted 20 November 2013; Published 21 January 2014

Academic Editor: Madhav Bhatia

Copyright (c) 2014 Si Jack Chong et al. This is an open access article distributed under the Creative Commons Attribution License, which permits unrestricted use, distribution, and reproduction in any medium, provided the original work is properly cited.

\begin{abstract}
Burn injuries result in the release of proinflammatory mediators causing both local and systemic inflammation. Multiple organ dysfunctions secondary to systemic inflammation after severe burn contribute to adverse outcome, with the lungs being the first organ to fail. In this study, we evaluate the anti-inflammatory effects of Parecoxib, a parenteral COX-2 inhibitor, in a delayed fluid resuscitation burned rat model. Anaesthetized Sprague Dawley rats were inflicted with $45 \%$ total body surface area full-thickness scald burns and subsequently subjected to delayed resuscitation with Hartmann's solution. Parecoxib (0.1, 1.0, and $10 \mathrm{mg} / \mathrm{kg}$ ) was delivered intramuscularly $20 \mathrm{~min}$ after injury followed by $12 \mathrm{~h}$ interval and the rats were sacrificed at $6 \mathrm{~h}, 24 \mathrm{~h}$, and $48 \mathrm{~h}$. Burn rats developed elevated blood cytokines, transaminase, creatinine, and increased lung MPO levels. Animals treated with $1 \mathrm{mg} / \mathrm{kg}$ Parecoxib showed significantly reduced plasma level of CINC-1, IL-6, PGEM, and lung MPO. Treatment of $1 \mathrm{mg} / \mathrm{kg}$ Parecoxib is shown to mitigate systemic and lung inflammation without significantly affecting other organs. At present, no specific therapeutic agent is available to attenuate the systemic inflammatory response secondary to burn injury. The results suggest that Parecoxib may have the potential to be used both as an analgesic and ameliorate the effects of lung injury following burn.
\end{abstract}

\section{Introduction}

Burn injury results in increased microvascular permeability leading to edema formation due to the loss in plasma fluid to the interstitial space [1]. Timely and early resuscitation of burn shock is effective in restoring normal tissue perfusion. However, severe burn victims are in pain, uncooperative, and unable to seek help that may delay evacuation. When resuscitation is delayed, recovery can be complicated by multiple end-organ failure due to systemic inflammation after severe burn and systemic inflammatory response syndrome (SIRS) has remained the primary cause of death in critically injured patients, with acute respiratory distress syndrome (ARDS) as the leading cause $[2,3]$. An early management of burn injury is essential for the good prognosis of burn patient. It has been reported that early control of inflammation after burn improves pulmonary function and survival $[4,5]$.
Consistent in these findings, Cyclooxygenase-2 (COX-2) has been shown to mediate inflammatory process through prostaglandins release after burn injury and inhibition of COX-2 attenuated proinflammatory cytokines, chemokines, and acute lung injury in burn-injured mice [6-8]. Parecoxib, a nonsteriodial anti-inflammatory drug (NSAID) indicated for postoperative pain, selectively blocks off the action of COX2 enzyme has been of interest on early burn management [9]. Recently, it was shown that burn injury induces COX-2 expression in central nervous system [10] and Parecoxib has been shown to have neuroprotective properties [11], although anti-inflammatory drugs for early burn management have been proposed but hitherto poorly studied and the effects of NSAID on SIRS after burn injury remain largely unknown. If effective, Parecoxib can be used both as an analgesic and ameliorate the effects of SIRS and ARDS in early burn management. On the basis that there are no reports on 
the effects of anti-inflammatory agent in the early management of burn injury with delayed resuscitation, the development of a rat model that consistently demonstrates burninduced SIRS/ARDS and survives for 48 hours sufficient for the evaluation of acute burn management modalities was conducted. The treatment efficacy of Parecoxib in animals following acute burns injury was evaluated in the present study.

\section{Material and Methods}

The experimental procedures were approved by DSO National Laboratories Institutional Animal Care and Use Committee.

2.1. Burn Injury Rat Model. Adult male Sprague Dawley rats (325-350 g) were acclimatised for one week before experiments. Animals were anesthetized with $100 \mathrm{mg} / \mathrm{kg}$ Ketamine and $7.5 \mathrm{mg} / \mathrm{kg}$ Diazepam, intraperitoneally (i.p.). The dorsal and ventral surfaces of the animals were shaved with clippers. The rats were placed into a customised mould that exposed $45 \%$ of the total body surface area (TBSA) calculated based on Meeh's formula [12]. Previous studies have shown that severe burn of more than 40\% TBSA inflicted ARDS and SIRS in humans $[2,3,13]$ and animals [14-16]. The mould was placed in $98^{\circ} \mathrm{C}$ to $100^{\circ} \mathrm{C}$ water, scalding the back for $10 \mathrm{~s}$ and the abdomen for $4 \mathrm{~s}$. Forty $\mathrm{mL} / \mathrm{kg}$ of Hartmann's solution $\left(131 \mathrm{mmol} / \mathrm{L} \mathrm{Na}^{+}, 5 \mathrm{mmol} / \mathrm{L} \mathrm{K}^{+}, 2 \mathrm{mmol} / \mathrm{L} \mathrm{Ca}^{2+}, 111 \mathrm{mmol} / \mathrm{L}\right.$ $\mathrm{Cl}^{-}$, and $29 \mathrm{mmol} / \mathrm{L} \mathrm{HCO}_{3}{ }^{2-}$, B. Braun Melsungen $\mathrm{AG}$, Melsungen, Germany) was administered i.p. half at $1 \mathrm{~h}$ after burn and the remaining half at $8 \mathrm{~h}$ after burn. Unburned rats (Sham) serving as controls were subjected to the same procedures except that they were exposed to $24^{\circ} \mathrm{C}$ water. After burn injury, the animals were placed in warm incubators $\left(30^{\circ} \mathrm{C}\right.$ to $\left.33^{\circ} \mathrm{C}\right)$ to prevent hypothermia and were allowed feed and water ad libitum. The rats were monitored for pain and distress and the survival rate of the animals was monitored over $48 \mathrm{~h}$.

2.2. Parecoxib Treatment. The austere condition of the disaster site may delay evacuation time and limit the access for medics to perform intravenous administration. On the basis that an easier method of drug delivery is necessary, the treatment efficacy of early intramuscular administration of Parecoxib on burn injury was examined. The burned animals were injected intramuscularly (i.m.) with Parecoxib $(0.1 \mathrm{mg} / \mathrm{kg}, 1.0 \mathrm{mg} / \mathrm{kg}$, and $10 \mathrm{mg} / \mathrm{kg})$ or saline at $20 \mathrm{~min}$, $12 \mathrm{~h}, 24 \mathrm{~h}$, and $36 \mathrm{~h}$ after burn. Unburned animals were also similarly injected i.m. $10 \mathrm{mg} / \mathrm{kg}$ Parecoxib as control.

2.3. Blood Analyses and Perfusion. At designated time points after burn injury, the animals were anaesthetized with Ketamine and Diazepam (75 and $10 \mathrm{mg} / \mathrm{kg}$, resp., i.p.), the carotid artery was cannulated, and $0.3 \mathrm{~mL}$ of heparinized arterial blood was collected for blood gases analysis using the i-STAT Portable Clinical Analyzer (Abbott Laboratories Inc., NJ, USA). Blood parameters, lactate, blood urea nitrogen (BUN), and $\mathrm{pH}$ were measured. Three milliliters of blood with EDTA were also collected via the carotid artery for other analyses, with fluid replacement using heparinized saline, shortly before perfusion with saline. The collected blood was centrifuged and clean plasma was aliquoted and stored in $-80^{\circ} \mathrm{C}$ for future assays. The animals were then perfused via transcardial perfusion with saline until the lungs, liver, and kidneys were clear of blood. The required organs were removed and soaked in $10 \%$ buffered formalin for fixation, prior to histological examination.

2.4. Histological Examination. The formalin-fixed tissue samples of lung, kidney, and liver, were dehydrated in ascending series of alcohol, cleared with xylene and embedded in paraffin wax. Paraffin sections of $4 \mu \mathrm{m}$ thick were then cut and dried in the oven overnight. For general morphology analysis, sections were stained in hematoxylin and eosin. Immunohistochemical stain of Myeloperoxidase (MPO) was also performed on lung sections. Polyclonal rabbit MPO antibody (Thermo Scientific, IL, USA) at 1:100 dilution was applied to the sections followed by antibody detection using the Envision+ anti-rabbit HRP polymer kit (DAKO UK Ltd., Cambridgeshire, UK). Sections were then visualized with 3,3'-diaminobenzidine, dehydrated, and mounted for viewing under microscope. A trained pathologist without prior knowledge of the experiment groups counted the MPOpositive polymorphonucleated cells in six random fields per slide using a 20x objective lens. The average value of MPOpositive cells was computed from at least five animals per experiment group.

2.5. Tissue Myeloperoxidase Activity. The tissues (lung, liver, and kidney) were separated and blotted on filter paper to remove excess fluid. Fifty milligrams of tissue samples were homogenized in $1 \mathrm{~mL}$ MPO buffer $(50 \mathrm{mM}$ potassium phosphate buffer, $0.5 \%$ hexadecyltrimethylammonium bromide, and $\mathrm{pH}$ 6.0) on ice. The homogenate was frozen in liquid nitrogen and thawed to room temperature four times before sonicating on ice. After sonication, the samples were centrifuged at $10,000 \mathrm{~g}$ at $4^{\circ} \mathrm{C}$ for $10 \mathrm{~min}$. The supernatant $(50 \mu \mathrm{L})$ containing the solubilized MPO was incubated in the dark with $50 \mu \mathrm{L}$ of tetramethylbenzidine (Sigma, St. Louis, MO, USA) substrate for $2 \mathrm{~min}$ and the reaction was stopped with $50 \mu \mathrm{L} \mathrm{H}_{2} \mathrm{SO}_{4}$. The absorbance was then read at $450 \mathrm{~nm}$ in room temperature with a colorimetric reader. The quantification of MPO was conducted using human MPO (number M-6908, Sigma, St. Louis, MO, USA) as standard.

2.6. Plasma Metabolic Substrates and Chemokine Expression. Concentrations of alanine aminotransferase (ALT), aspartate aminotransferase (AST), and creatinine in plasma samples were determined with a Cobas c111 reader (Roche, Rotkreuz, Switzerland) according to manufacturer's instructions. Plasma samples were also assayed for C-reactive protein (CRP; Biovendor, Brno, Czech Republic), interleukin6 (IL-6; R\&D Systems, MN, USA), cytokine-induced neutrophil chemoattractant-1 (CINC-1; R\&D Systems, MN, USA), and prostaglandin E2 (PGE2, Cayman Chemical, MI, USA) according to manufacturers' instructions. 
2.7. Lung Cyclooxygenase-2 and Prostaglandin E2 Expression. The actions of Parecoxib on burn-induced lung injury were examined. The lung homogenate of the animal samples was assayed for cyclooxygenase-2 (COX-2; IBL International, Hamburg, Germany) and prostaglandin E2 (PGE2, Cayman Chamical, MI, USA) using enzyme-linked immunosorbent assay technique according to manufacturer's instructions.

2.8. Statistical Analysis. Data are presented as mean \pm standard error mean (SEM). Statistical analysis was performed by one-way analysis of variance (ANOVA, post-hoc Bonferroni test) for comparisons among multiple groups. The survival rate of the animals was compared using Kaplan-Meier analysis and statistical significance was calculated using Wilcoxon (Gehan) statistic (SPSS 15.0, IBM Corporation, NY, USA). For comparisons between 2 groups, the independent samples $t$-test was performed. $P$ value $<0.05$ was considered statistically significant.

\section{Results}

3.1. Survival Rate. The survival rate of the animals was compared with Kaplan-Meier analysis as shown in Figure 1. Burned animals had $56.5 \%$ survival after 48 hours following burns. In comparison to the control animals, the rats treated with $0.1 \mathrm{mg} / \mathrm{kg}$ and $1.0 \mathrm{mg} / \mathrm{kg}$ Parecoxib showed improved survival of $62.5 \%(P$ value $=0.270)$ and $66.6 \%(P$ value $=0.136)$, respectively. The surviving burn animals treated with $1.0 \mathrm{mg} / \mathrm{kg}$ Parecoxib were found to have reduced weight loss and increased food and water intake compared to the rest of the burn groups (personal observation). Burned animals treated with $10 \mathrm{mg} / \mathrm{kg}$ Parecoxib had significantly lower $(P$ value $=0.001)$ survival rate $(23.5 \%)$ compared to the burn control animals.

3.2. Parameters for Acute Lung Injury. Figure 2 shows analyses of blood gases, lung PGE2 levels, and lung COX2 levels of the burned animals over a period of $48 \mathrm{~h}$. The acute lung injury of the burn animals was examined. It was found that $24 \mathrm{~h}$ following burn induced decreased $\mathrm{pO}_{2}$ and increased $\mathrm{pCO}_{2}$ in arterial blood of animals receiving saline injection. Treatment of $0.1 \mathrm{mg} / \mathrm{kg}$ and $1.0 \mathrm{mg} / \mathrm{kg}$ Parecoxib did not seem to attenuate the burn-induced changes in the blood gases. However, burn animals treated with $10 \mathrm{mg} / \mathrm{kg}$ Parecoxib showed deleterious effects of further decreased $\mathrm{pO}_{2}$ and elevated $\mathrm{pCO}_{2}$ up to $48 \mathrm{~h}$ compared to the burn control animals. As a COX-2 selective inhibitor, Parecoxib reduces inflammation via decreasing COX-2 activity and the downstream PGE2 formation. The lung PGE2 and COX-2 levels were significantly higher in the burn + saline group at $6 \mathrm{~h}$ when compared to the Sham animals and the levels gradually decreased to normal level $48 \mathrm{~h}$ (Figures 2(c) and 2(d)). Treatment of Parecoxib dose dependently reduced the level of PGE2 in $6 \mathrm{~h}$ following burn with $1.0 \mathrm{mg} / \mathrm{kg}$ Parecoxib and $10 \mathrm{mg} / \mathrm{kg}$ Parecoxib induced about 20 and 40 percentreduction, respectively.
3.3. Neutrophil Infiltration in the Lungs of Burned Animals. The MPO levels in the lungs of the burned rats were examined. Figure 3(a) showed the representative histological MPO staining of lungs at $6 \mathrm{~h}$ following burn and the number of stained cell was quantified at various time points (Figure 3(b)). Burned animals treated with saline had increased levels of MPO activity in the lung at $6 \mathrm{~h}$ and the level gradually decreased over $48 \mathrm{~h}$. The anti-inflammatory action of Parecoxib was dose-dependent with $1.0 \mathrm{mg} / \mathrm{kg}$ Parecoxib showing highest reduction in neutrophil infiltration in the burned animals and $10 \mathrm{mg} / \mathrm{kg}$ group had increased lung inflammation. The lung MPO activity of the lung samples was also quantified by colorimetric assay as shown in Figure 3(c).

3.4. Blood Transaminases and Liver MPO Activity. The plasma AST and ALT increased significantly at $6 \mathrm{~h}$ after burn and gradually decreased over $48 \mathrm{~h}$. At $48 \mathrm{~h}$, the control burn animals showed significantly higher plasma ALT level (Figures 4(a) and 4(b)). Burn injury did not attenuate hepatic neutrophil infiltration as the liver MPO level in the burned animals remained comparable to the Sham animals over $48 \mathrm{~h}$ (Figure $4(\mathrm{c})$ ). As expected, treatment of $0.1 \mathrm{mg} / \mathrm{kg}$ and $1.0 \mathrm{mg} / \mathrm{kg}$ Parecoxib did not seem to attenuate the burninduced changes in the parameters for liver function at $6 \mathrm{~h}$. However, burn animals treated with high dose of Parecoxib $(10 \mathrm{mg} / \mathrm{kg})$ showed deleterious effects of further increases in AST, ALT, and liver MPO at $6 \mathrm{~h}$. The MPO levels remained significantly higher in the $10 \mathrm{mg} / \mathrm{kg}$ Parecoxib-treated burn animals at $24 \mathrm{~h}$ and $48 \mathrm{~h}$. Elevated ALT level is a specific indicator for hepatic injury $[17,18]$. It was reported that overdose of several drugs (including NSAIDs) is associated with elevated ALT levels and hepatotoxicity [19-22]. The data seems to suggest that high dose of Parecoxib $(10 \mathrm{mg} / \mathrm{kg})$ inflicted liver damage in burn animals in a similar manner to other NSAIDs.

3.5. Parameters for Acute Renal Damage. The arterial plasma $\mathrm{pH}$ of the burn animals dropped significantly at $6 \mathrm{~h}$ and was restored back to Sham level $24 \mathrm{~h}$ after burn injury (Figure 5(a)). The plasma creatinine, BUN, and kidney MPO levels raised significantly $6 \mathrm{~h}$ following burn and decreased gradually over $48 \mathrm{~h}$ (Figures $5(\mathrm{~b})-5(\mathrm{~d})$ ). Treatment of $0.1 \mathrm{mg} / \mathrm{kg}$ and $1.0 \mathrm{mg} / \mathrm{kg}$ Parecoxib did not seem to attenuate the burn-induced changes in the parameters for kidney function at $48 \mathrm{~h}$. However, burn animals treated with $10 \mathrm{mg} / \mathrm{kg}$ Parecoxib showed deleterious effects of further decrease in arterial plasma $\mathrm{pH}$ and increases in plasma creatinine, BUN, and kidney MPO compared to the burn control animals.

3.6. Plasma Cytokines. The plasma proinflammatory cytokines profile over $48 \mathrm{~h}$ following burn was examined. Figures 6(a)-6(d) showed that plasma CRP, IL-6, CINC-1, and PGE2 were elevated gradually and peaked at $48 \mathrm{~h}$ following burn. The levels of these proinflammatory cytokines were significantly lowered in Parecoxib-treated burned animals in a dose-dependent manner, with burned animals 


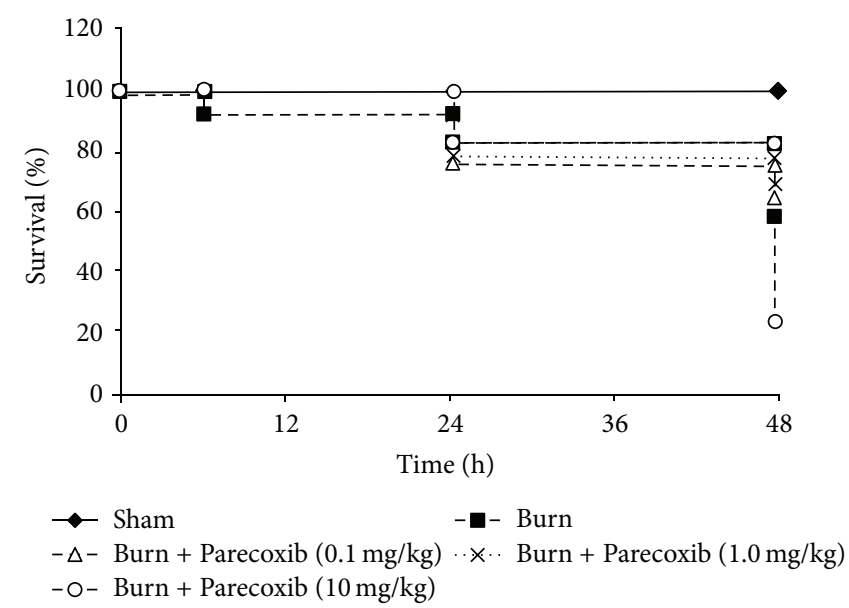

FIGURE 1: Effect of intramuscularly administered Parecoxib on survival rate of burned animals over $48 \mathrm{~h}$. Animals were divided into five groups of thirty animals per group. Animals in the burn groups were exposed to $98^{\circ} \mathrm{C}$ to $100^{\circ} \mathrm{C}$ water, scalding the back for $10 \mathrm{~s}$ and the abdomen for $4 \mathrm{~s}$. Hartmann's solution $(40 \mathrm{~mL} / \mathrm{kg})$ was administered i.p. half at $1 \mathrm{~h}$ after burn and the remaining half at $8 \mathrm{~h}$ after burn. The burned animals were injected i.m. with saline, $0.1 \mathrm{mg} / \mathrm{kg}, 1.0 \mathrm{mg} / \mathrm{kg}$, or $10 \mathrm{mg} / \mathrm{kg}$ Parecoxib at $20 \mathrm{~min}, 12 \mathrm{~h}, 24 \mathrm{~h}$, and $36 \mathrm{~h}$ after burn. Sham animals were exposed to $24^{\circ} \mathrm{C}$ water and similarly injected i.m. $10 \mathrm{mg} / \mathrm{kg}$ Parecoxib as control. The survival rate of the animals was compared using Wilcoxon (Gehan) statistic.

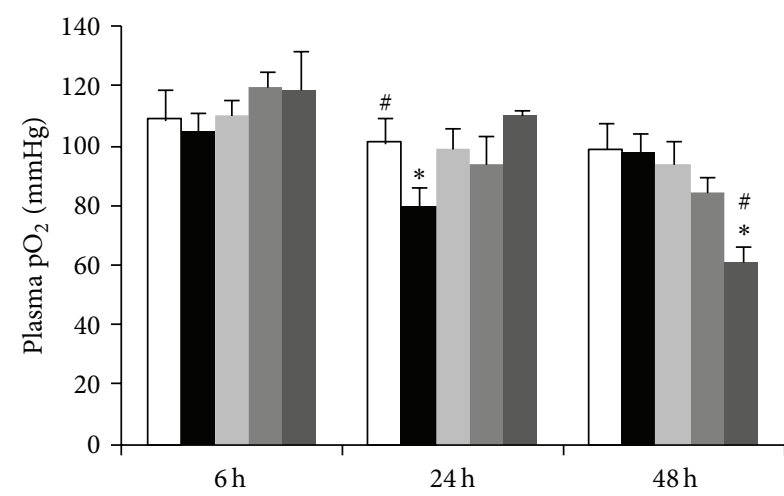

(a) $\mathrm{pO}_{2}$

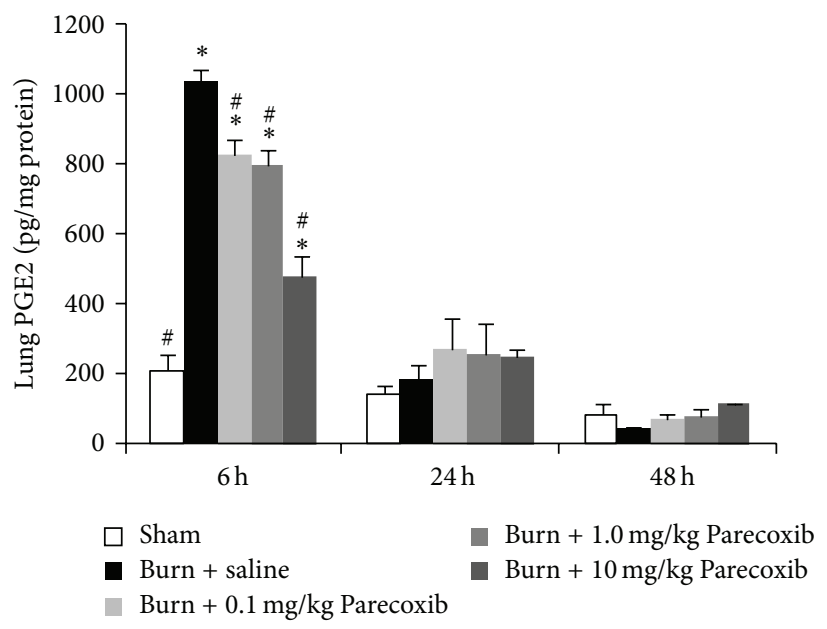

(c) Lung PGE2

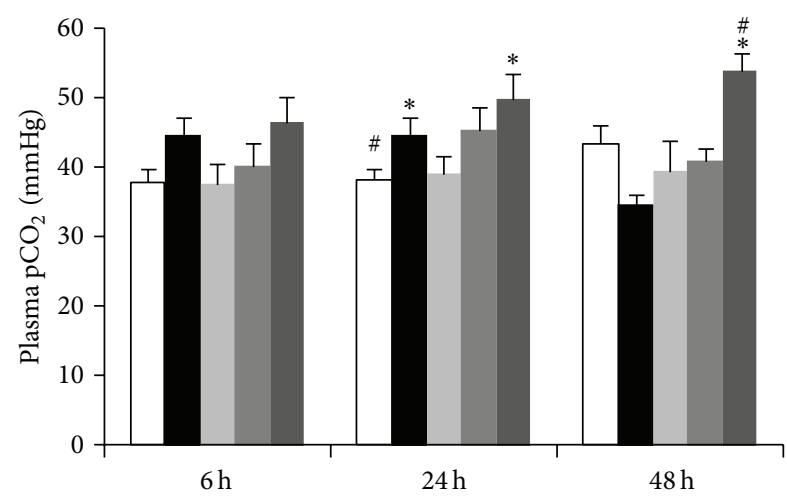

(b) $\mathrm{pCO}_{2}$

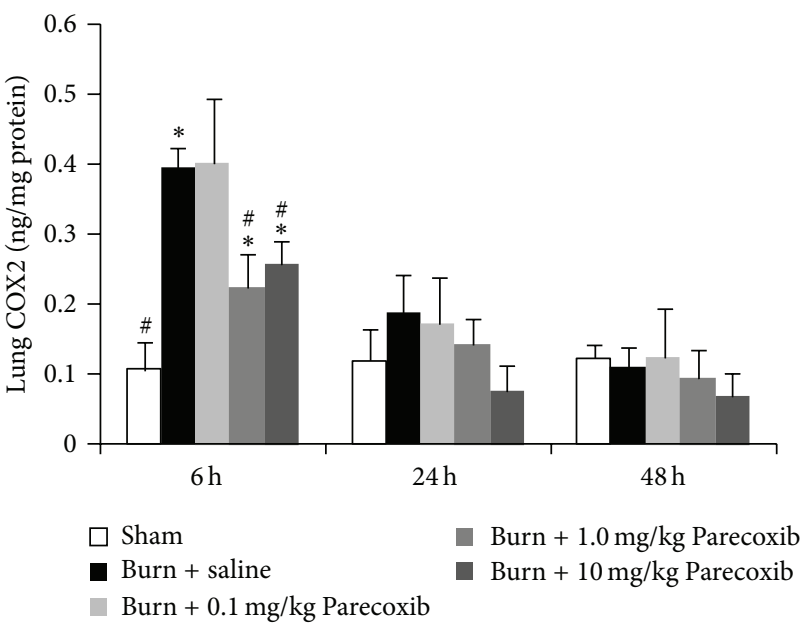

(d) Lung COX2

FIGURE 2: Changes in arterial blood gases and metabolic parameters over $48 \mathrm{~h}$ after burn injury. (a) $\mathrm{pCO}_{2}$; (b) $\mathrm{pCO}_{2}$; (c) lung PGE2; and (d) lung COX2. ${ }^{*}$ Significantly different from Sham group. ${ }^{*}$ Significantly different from burn + saline group $(P<0.05$, one-way ANOVA, Bonferroni post-hoc test). 

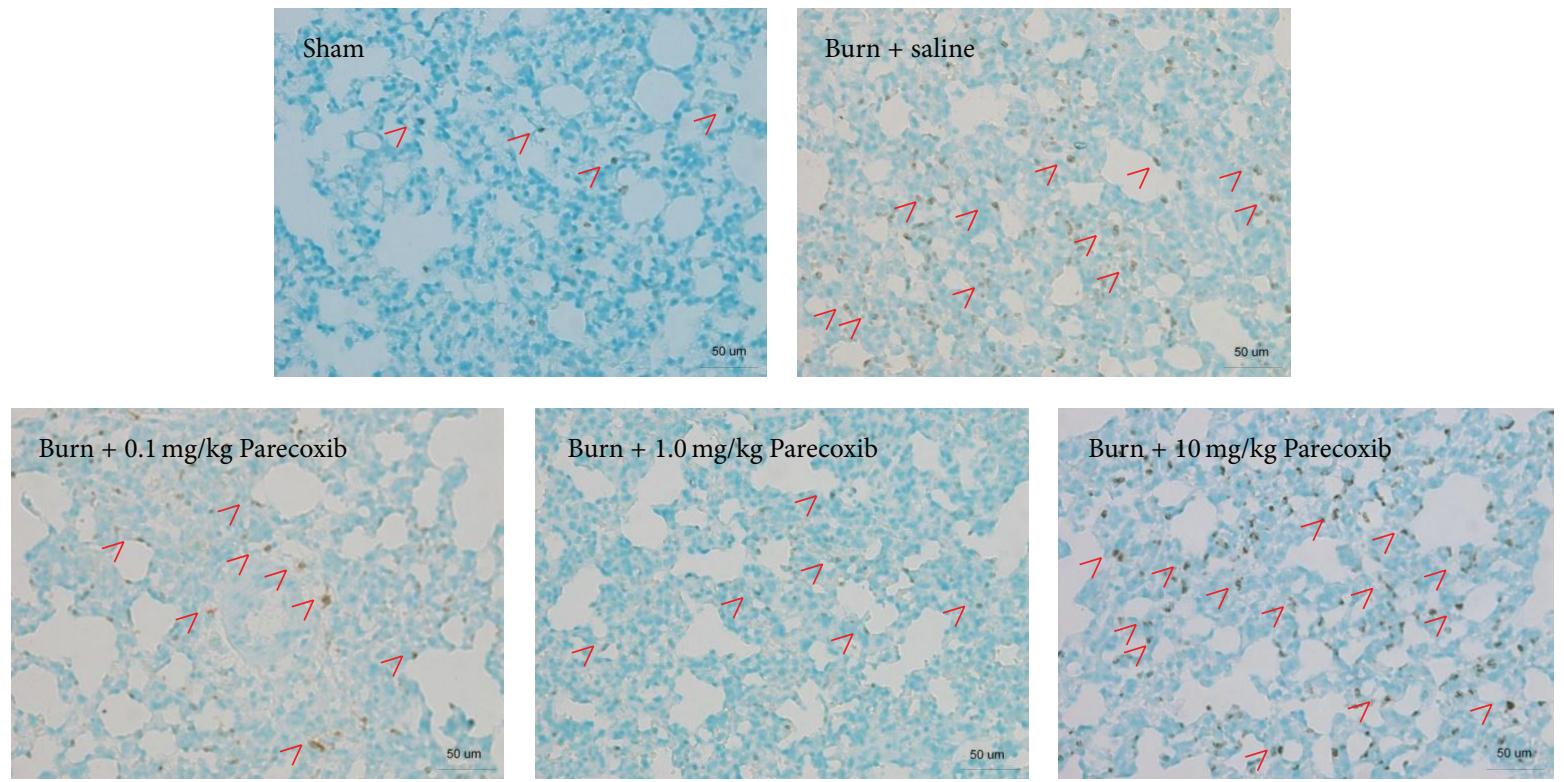

(a) Lung MPO activity staining

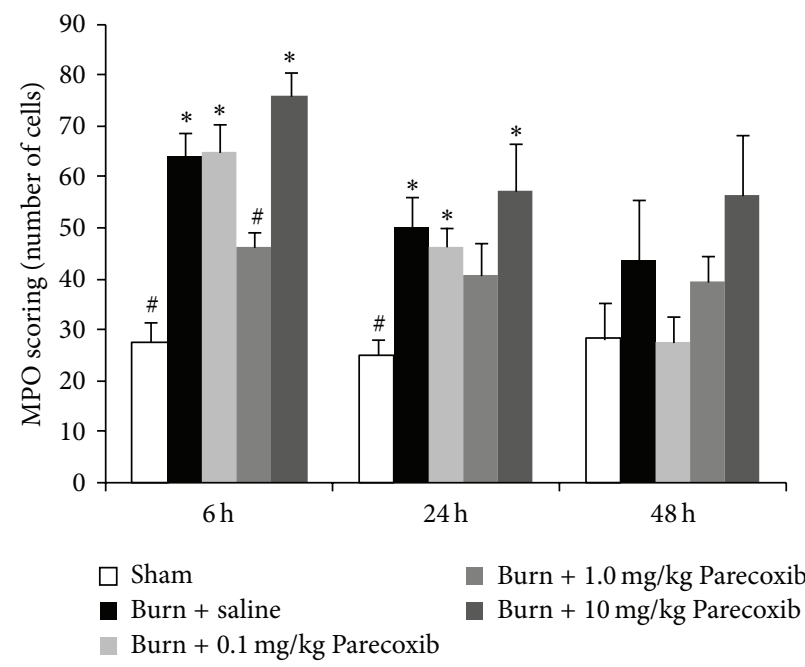

(b) Lung MPO scoring

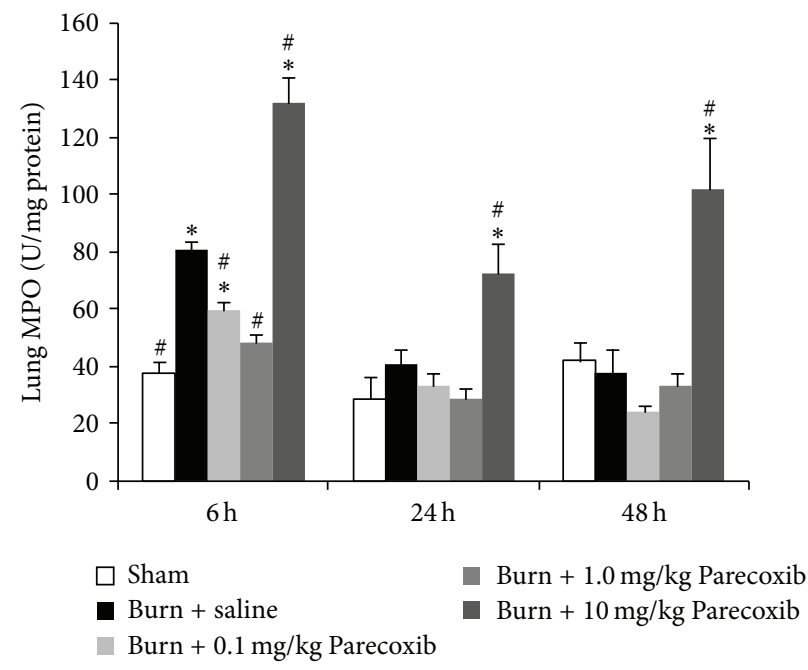

(c) Lung MPO quantification

FIGURE 3: MPO quantification in lung tissue as an indicator for pulmonary neutrophil sequestration. (a) MPO activity staining at $6 \mathrm{~h}$, (b) lung tissue stained for MPO and number of MPO positive cells quantified, and (c) MPO activity of the lung tissue. Red arrowhead represents neutrophil infiltration. * Significantly different from Sham group. ${ }^{*}$ Significantly different from burn + saline group $(P<0.05$, one-way ANOVA, Bonferroni post-hoc test).

treated $10 \mathrm{mg} / \mathrm{kg}$ Parecoxib exhibiting lowest concentration of cytokines.

3.7. Histological Examination. Histological examination revealed that the major organs such as lung, liver, and kidney in animals of Sham group appeared structurally normal (Figure 7). Compared with the organs obtained from the Sham animals, significant tissue injuries were observed in all burn animals. At $6 \mathrm{~h}$ following burn, the liver and kidney showed oedema with loss of normal tissue structure. Pulmonary alveolar septal thickening and infiltration of inflammatory cells were also observed. Among all Parecoxib treated groups, burn animals treated with $1.0 \mathrm{mg} / \mathrm{kg}$ Parecoxib showed the least structural damages in these organs, while burn animals treated with $10 \mathrm{mg} / \mathrm{kg}$ showed the most severe organ damages. Similar patterns were observed at $24 \mathrm{~h}$ and $48 \mathrm{~h}$ following burn (data not shown).

\section{Discussion}

In the present study, an acute burn rat model with delayed fluid resuscitation is developed in which the animals were subjected to a $45 \%$ TBSA burn and the SIRS indicators 


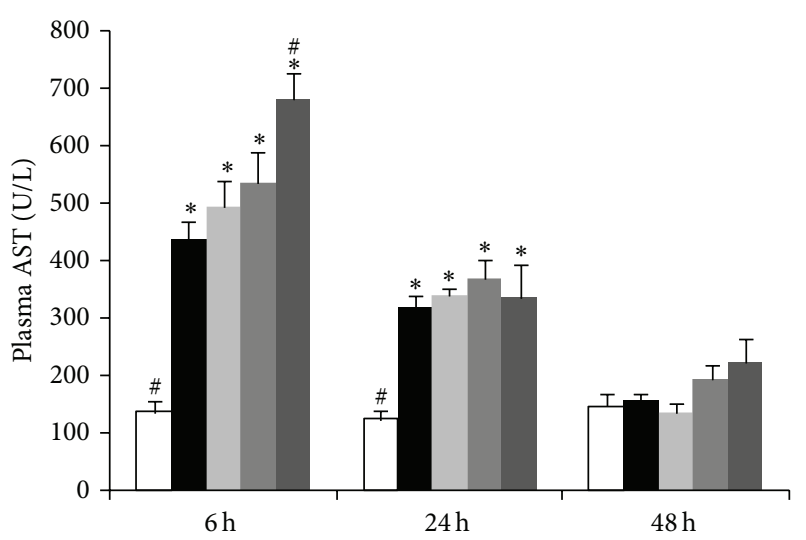

(a) AST

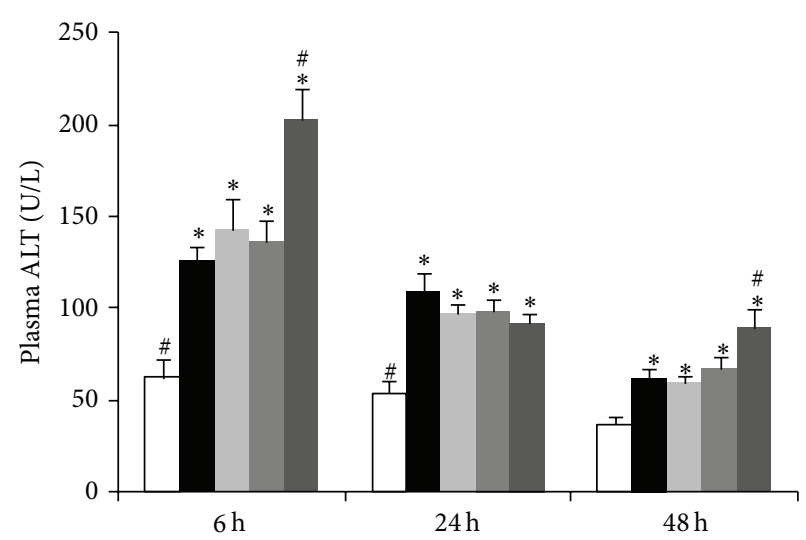

(b) ALT

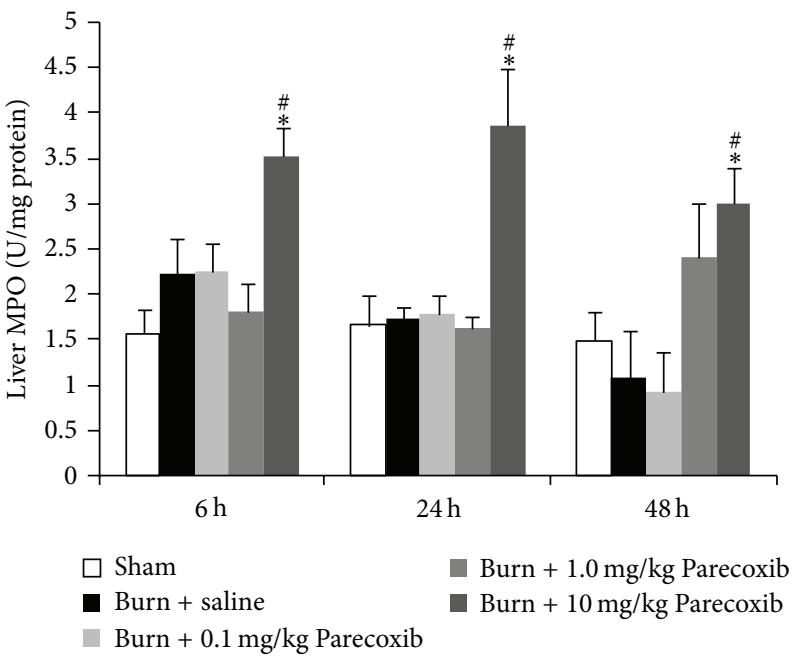

(c) $\mathrm{MPO}$

Figure 4: Changes in parameters for liver function over $48 \mathrm{~h}$ after burn injury. (a) AST; (b) ALT; (c) MPO. * Significantly different from Sham

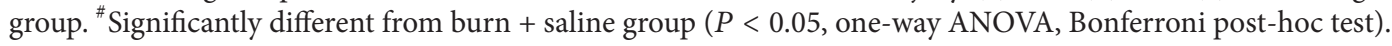

monitored for $48 \mathrm{~h}$. Many rodent models of scald burn have been previously established. In the study by Gauglitz et al., Sprague Dawley rats subjected to a $60 \%$ TBSA were tracked for immunological responses and were found to exhibit marked inflammatory response [23]. Further studies by other groups showed subsequent organ damage, including lung [24], kidney and liver [25], and heart [16], suggesting SIRS arising from the burn insult. However, the burn model in most of the studies had high mortality rate and study of SIRS was not adequate. In this study, we developed the first small animal burns model that consistently produced SIRS which developed into multiple organ dysfunctions (MODS). The fluid resuscitation in this burn model is based on the Parkland formula, devised by Baxter [26], which calculates the amount of fluid required to resuscitate a burned patient based on percentage burn $(4 \mathrm{~mL} / \mathrm{kg} /$ percentage burn of isotonic crystalloid). However, resuscitation with large volumes of crystalloid has numerous adverse consequences, including worsening of burn oedema and intra-abdominal hypertension [27-30]. We observed more than $50 \%$ of the burned animals survived at the end of 2 days, developed SIRS and multiple organs failure in the first six hours. This model yielded consistently elevated and quantifiable parameters damages similar to Sequential Organ Failure Assessment (SOFA) scoring. The lung, liver, and kidney damages of the survived burn animals were assessed for multiple organs failure and plasma inflammatory cytokines assessed for SIRS. The burn animals developed ALI with increased levels of lung PGE2, COX2, and MPO activity at $6 \mathrm{~h}$ following burn, followed by a fall in arterial $\mathrm{pO}_{2}$ and rise in $\mathrm{pCO}_{2}$ at $24 \mathrm{~h}$. The burn inflicted liver damage animals with increased AST and ALT levels at $6 \mathrm{~h}$ and gradually declined over $48 \mathrm{~h}$. Acute renal damage were also observed with changes in the blood $\mathrm{pH}, \mathrm{BUN}$, creatinine levels, and kidney MPO level during the first $6 \mathrm{~h}$ after burn. The indicators for MODS gradually decreased as the survived burned animals were recovering over $48 \mathrm{~h}$. The results showed that early intervention on burn inflicted MODS increased the animal survival in delayed fluid resuscitation. This novel model will provide a good platform for the testing of various therapeutic agents in 


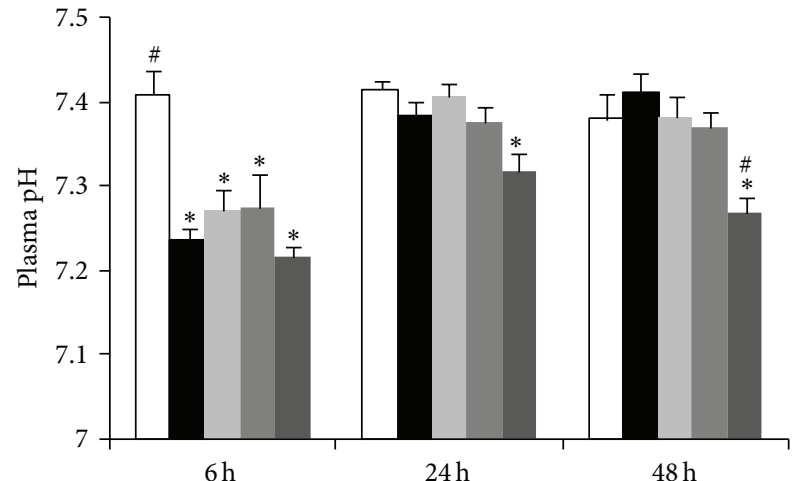

(a) $\mathrm{pH}$

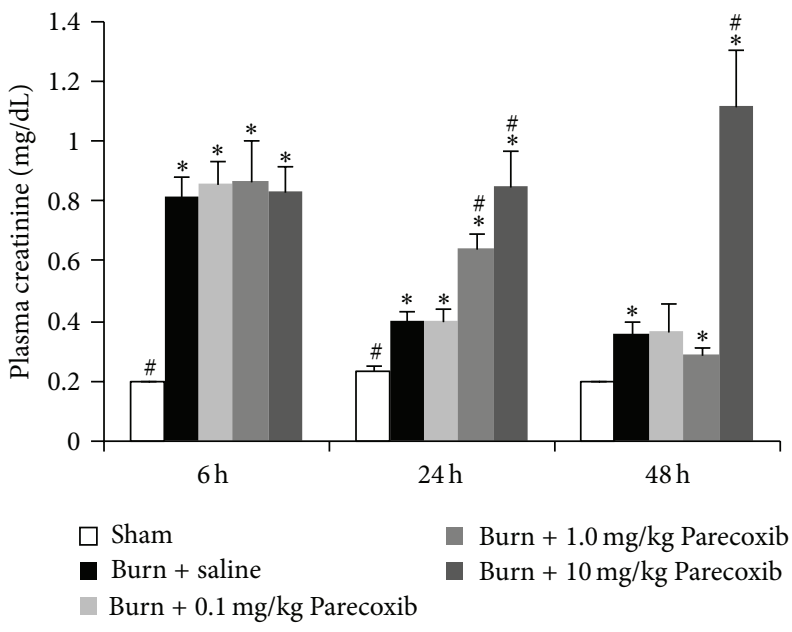

(c) Creatinine

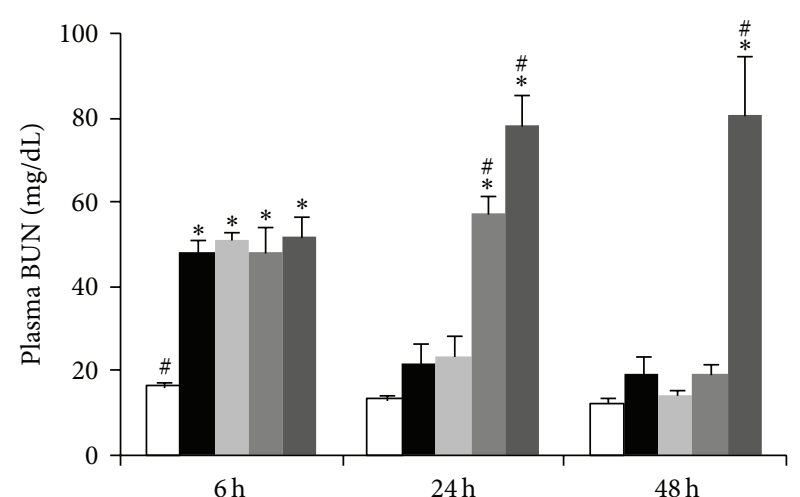

(b) BUN

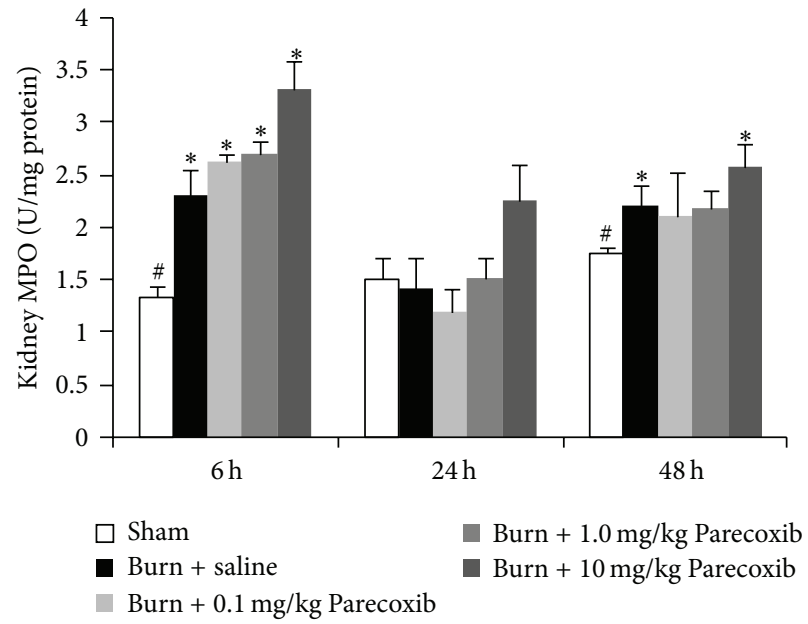

(d) MPO

FIGURE 5: Changes in parameters for kidney function over $48 \mathrm{~h}$ after burn injury. (a) Plasma pH; (b) BUN; (c) plasma creatinine; and (d) kidney MPO. * Significantly different from Sham group. " Significantly different from burn + saline group $(P<0.05$, one-way ANOVA, Bonferroni post-hoc test).

the early treatment of SIRS and the burn related MODS in the future.

The anti-inflammatory effects of Parecoxib on ALI and MODS were examined in the present study. Similar to other burn studies, the circulating cytokines were elevated after burn injury and peaked at $24 \mathrm{~h}$ or $48 \mathrm{~h}$ [31-33]. It is proposed that systemic inflammation is initiated by the release of local inflammatory mediators in thermal injury [34]. In this study, Parecoxib was shown to suppress tissue inflammation at $6 \mathrm{~h}$ after severe burn and subsequently reduced SIRS at $48 \mathrm{~h}$. It was found that $1.0 \mathrm{mg} / \mathrm{kg}$ Parecoxib specifically attenuated ALI $6 \mathrm{~h}$ after burn. In addition, as a specific COX2 inhibitor, Parecoxib dose dependently reduced the levels of ex vivo pulmonary COX-2 and PGE2 at $6 \mathrm{~h}$ and in vivo proinflammatory cytokine levels at $48 \mathrm{~h}$. Burn injury results in the release of proinflammatory mediators causing local and systemic inflammation and edema. Mortality and morbidity resulting from multiple end-organ failure due to systemic inflammation after severe burn have remained the primary cause of death in critically injured individuals, with the lungs being the first organ to fail $[2,3]$. The most common cause of death in a burn casualty is not from direct damage to the tissue but from complications of respiratory failure. Parecoxib has been widely adopted by both the European and Australia anaesthesia and intensive care community being the first parenteral COX2 specific NSAID that can be used to alleviate postoperative pain $[35,36]$. The treatment of intravenous and intramuscular of Parecoxib for acute postoperative pain in adults was reviewed and concluded from several clinical studies that the effective dose is between 0.5 to $0.8 \mathrm{mg} / \mathrm{kg}$, corrected by weight [37]. The dose of $1.0 \mathrm{mg} / \mathrm{kg}$ Parecoxib, observed to mitigate ALI and SIRS in the burn rats, is similar to the reported efficacious dose, making it a practical anaesthesia and anti-inflammatory pharmacological agent against ALI for burn patients. The anti-inflammatory effect of Parecoxib was similarly reported in burn-injured WT mice and PPT-A $\mathrm{A}^{-}{ }^{-}$mice injected with substance P [9].

However, it is also revealed that high dose Parecoxib $(10 \mathrm{mg} / \mathrm{kg})$ inflicted higher mortality compared to the control burn animals. Despite the significant decrease in levels of plasma cytokines and prostaglandin E2, high dose Parecoxib paradoxically aggravates burn-induced MODS. This finding 


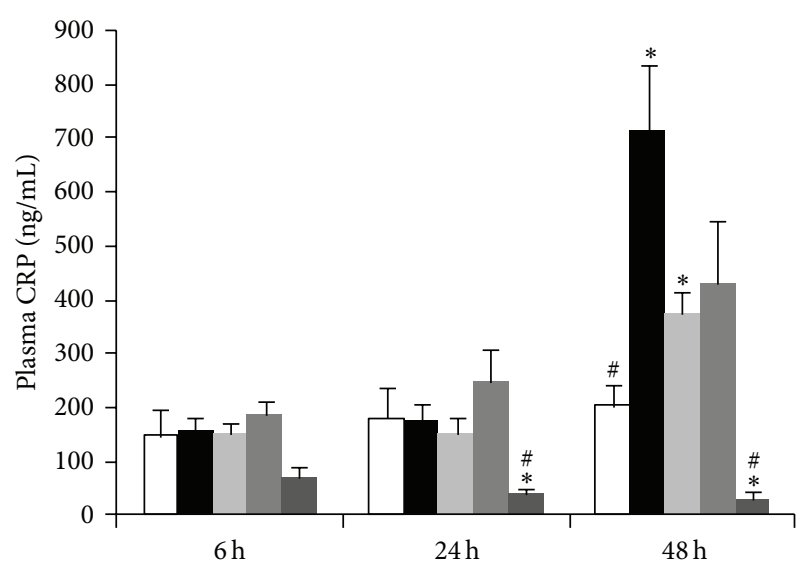

(a) CRP

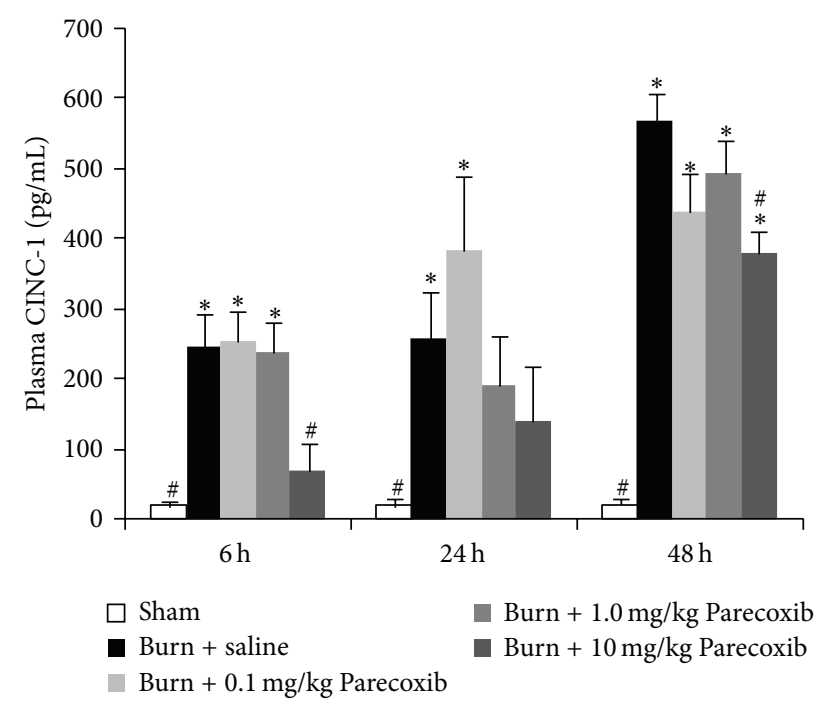

(c) CINC-1

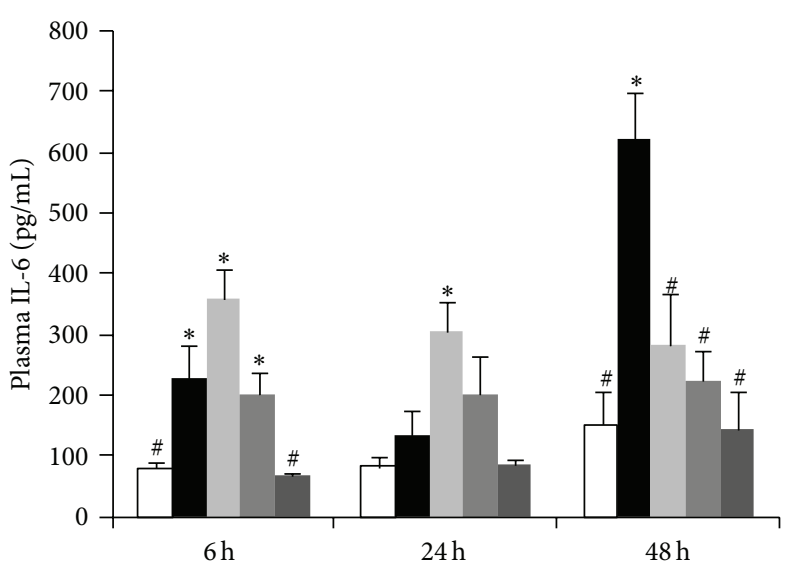

(b) IL-6

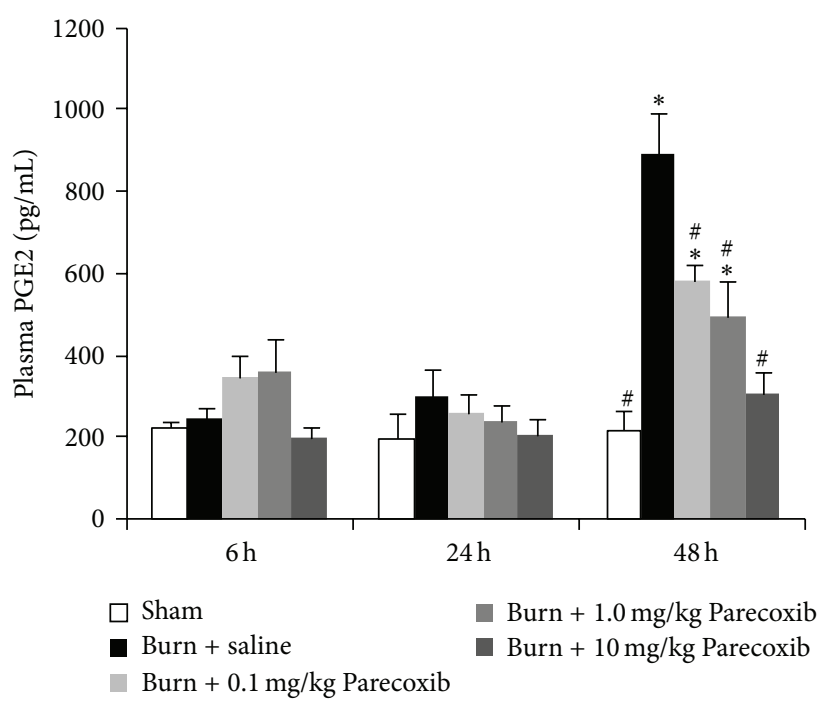

(d) PGE2

FIGURE 6: Changes in blood proinflammatory cytokines over $48 \mathrm{~h}$ after burn injury. (a) CRP; (b) IL-6; (c) CINC-1; and (d) PGE2. * Significantly different from Sham group. "Significantly different from burn + saline group $(P<0.05$, one-way ANOVA, Bonferroni post-hoc test).

that can be explained by prostaglandin E2 is a potent vasodilator and has autoregulatory control of blood flow to many tissues including the lungs, liver, and kidney [38]. It is well documented that prostaglandin inhibitors, NSAIDs, have minimal renal hemodynamic effect in basal condition, as prostaglandin level is low $[39,40]$. In pathological conditions of water depletion, synthesis of prostaglandin is stimulated by vasoconstrictors such as angiotensin II and norepinephrine [41]. NSAID administration, in such conditions, reduces tissue perfusion and exacerbates underlying organ dysfunction [42, 43]. Furthermore, pharmacokinetic analysis of these burn animals showed that the median peak serum Parecoxib concentration was reached $15 \mathrm{~min}$ after injection and significant changes were observed in the bioavailability and mean residence time of Parecoxib between the burn and nonburn rats receiving $10 \mathrm{mg} / \mathrm{kg}$ Parecoxib but not in the animals which receiving $1.0 \mathrm{mg} / \mathrm{kg}$ (data not shown). The data suggest that the burn animals received high dose Parecoxib had reduced hepatic metabolism and renal clearance of the drug.

\section{Conclusion}

The pathophysiology of MODS derived from burn-induced SIRS is extensively studied and the role of mediators which control the inflammatory response is largely understood. The use of anti-inflammatory agents to suppress burn-induced SIRS has not been successful due to the complex network and multiple actions of cytokines [44-46]. At present, no specific therapeutic agent is available to attenuate SIRS to burn injury. In this study, Parecoxib is shown to mitigate systemic and lung inflammation without significantly affecting other organs in the delayed fluid resuscitation burn model. 

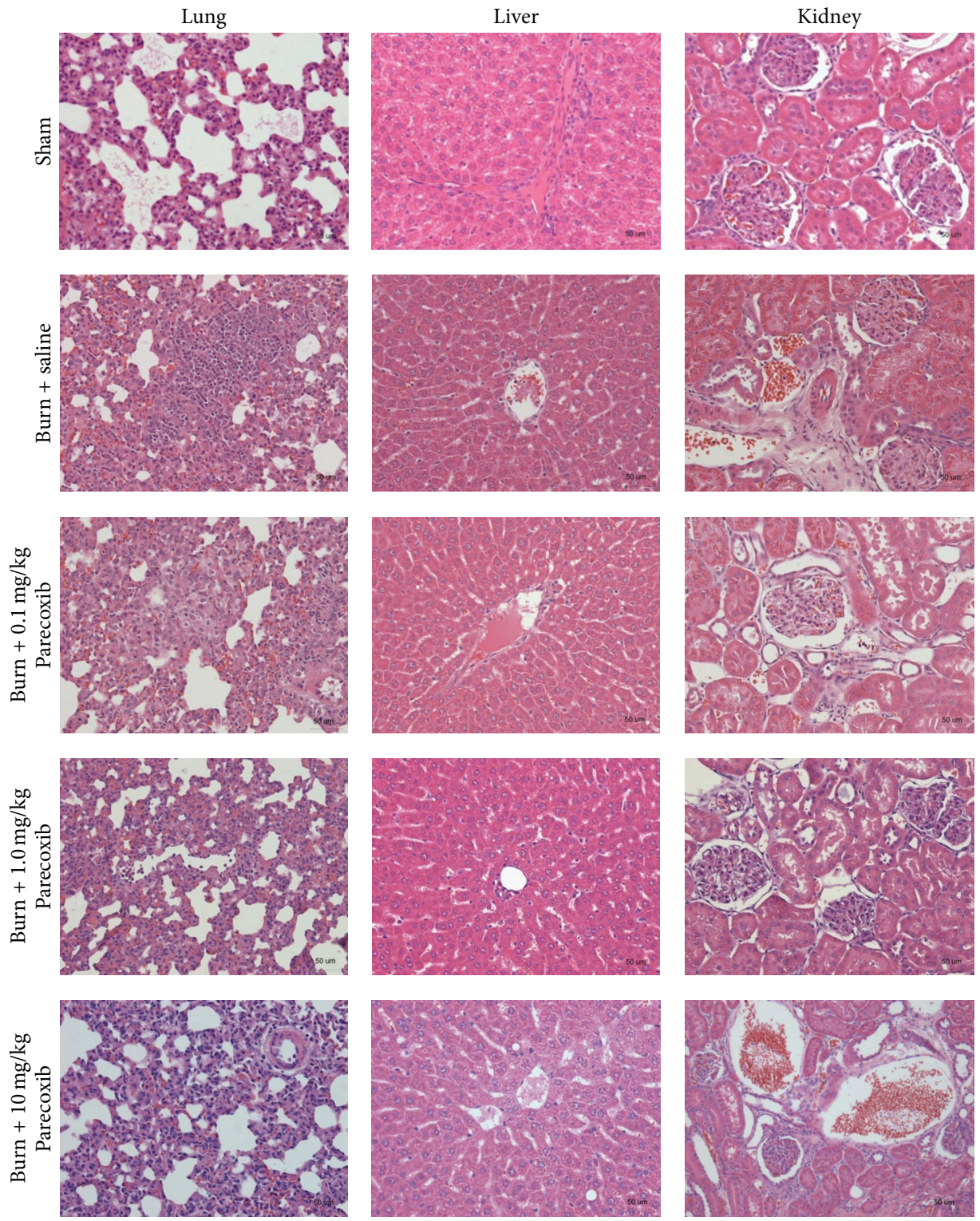

FIgURE 7: Histological examination of lung, liver, and kidney in Sham, burn + saline, burn $+0.1 \mathrm{mg} / \mathrm{kg}$ Parecoxib, burn $+1.0 \mathrm{mg} / \mathrm{kg}$ Parecoxib, and burn $+10 \mathrm{mg} / \mathrm{kg}$, at $6 \mathrm{~h}$ following burn.

The results suggest that Parecoxib may have the potential to be used both as an analgesic and ameliorate the effects of lung injury following burn. The therapeutic use of Parecoxib for ALI in severe burn casualty is possible, but its adverse effects should be closely monitored.

\section{Conflict of Interests}

The authors declare that there is no conflict of interests regarding the publication of this paper.

\section{References}

[1] R. H. Demling, "The burn edema process: current concepts," Journal of Burn Care and Rehabilitation, vol. 26, no. 3, pp. 207$227,2005$.
[2] R. H. Turnage, F. Nwariaku, J. Murphy, C. Schulman, K. Wright, and $\mathrm{H}$. Yin, "Mechanisms of pulmonary microvascular dysfunction during severe burn injury," World Journal of Surgery, vol. 26, no. 7, pp. 848-853, 2002.

[3] D. R. Dancey, J. Hayes, M. Gomez et al., "ARDS in patients with thermal injury," Intensive Care Medicine, vol. 25, no. 11, pp. 12311236, 1999.

[4] K. Ipaktchi, A. Mattar, A. D. Niederbichler et al., "Attenuating burn wound inflammation improves pulmonary function and survival in a burn-pneumonia model," Critical Care Medicine, vol. 35, no. 9, pp. 2139-2144, 2007.

[5] T. J. Murphy, H. M. Paterson, S. Kriynovich et al., "Linking the "two-hit" response following injury to enhanced TLR4 reactivity," Journal of Leukocyte Biology, vol. 77, no. 1, pp. 16-23, 2005. 
[6] L.-K. He, L. H. Liu, E. Hahn, and R. L. Gamelli, “The expression of cyclooxygenase and the production of prostaglandin E2 in neutrophils after burn injury and infection," Journal of Burn Care and Rehabilitation, vol. 22, no. 1, pp. 58-64, 2001.

[7] G. A. FitzGerald, "COX-2 and beyond: approaches to prostaglandin inhibition in human disease," Nature Reviews Drug Discovery, vol. 2, no. 11, pp. 879-890, 2003.

[8] T. A. Wilgus, M. S. Ross, M. L. Parrett, and T. M. Oberyszyn, "Topical application of a selective cyclooxygenase inhibitor suppresses UVB mediated cutaneous inflammation," Prostaglandins and Other Lipid Mediators, vol. 62, no. 4, pp. 367-384, 2000.

[9] S. W. S. Sio, S. F. Ang, J. Lu, S. Moochhala, and M. Bhatia, "Substance $\mathrm{p}$ upregulates cyclooxygenase-2 and prostaglandin E metabolite by activating ERK1/2 and NF- $\kappa \mathrm{B}$ in a mouse model of burn-induced remote Acute lung injury," Journal of Immunology, vol. 185, no. 10, pp. 6265-6276, 2010.

[10] Y. Ozaki-Okayama, K. Matsumura, T. Ibuki et al., "Burn injury enhances brain prostaglandin E2 production through induction of cyclooxygenase-2 and microsomal prostaglandin E synthase in cerebral vascular endothelial cells in rats," Critical Care Medicine, vol. 32, no. 3, pp. 795-800, 2004.

[11] J. Kelsen, K. Kjær, G. Chen et al., "Parecoxib is neuroprotective in spontaneously hypertensive rats after transient middle cerebral artery occlusion: a divided treatment response?" Journal of Neuroinflammation, vol. 3, article 31, 2006.

[12] H. L. Walker and A. D. Mason Jr., "A standard animal burn," Journal of Trauma, vol. 8, no. 6, pp. 1049-1051, 1968.

[13] N. Aikawa, Y. Shinozawa, and K. Ishibiki, "Clinical analysis of multiple organ failure in burned patients," Burns, vol. 13, no. 2, pp. 103-109, 1987.

[14] H. Baskaran, M. L. Yarmush, and F. Berthiaume, "Dynamics of tissue neutrophil sequestration after cutaneous burns in rats," Journal of Surgical Research, vol. 93, no. 1, pp. 88-96, 2000.

[15] A. J. Singer, E. Wang, B. R. Taira, N. Steinhauff, J. Rooney, and T. Zimmerman, "Controlled mild hypothermia prolongs survival in a rat model of large scald burns," Academic Emergency Medicine, vol. 18, no. 3, pp. 287-291, 2011.

[16] J.-P. Zhang, X. Ying, W.-Y. Liang et al., "Apoptosis in cardiac myocytes during the early stage after severe burn," The Journal of Trauma, vol. 65, no. 2, pp. 401-408, 2008.

[17] R. M. Green and S. Flamm, "AGA technical review on the evaluation of liver chemistry tests," Gastroenterology, vol. 123, no. 4, pp. 1367-1384, 2002.

[18] D. S. Pratt and M. M. Kaplan, "Evaluation of abnormal liverenzyme results in asymptomatic patients," The New England Journal of Medicine, vol. 342, no. 17, pp. 1266-1271, 2000.

[19] P. B. Watkins, N. Kaplowitz, J. T. Slattery et al., "Aminotransferase elevations in healthy adults receiving 4 grams of acetaminophen daily: a randomized controlled trial," Journal of the American Medical Association, vol. 296, no. 1, pp. 87-93, 2006.

[20] V. G. Athyros, K. Tziomalos, T. D. Gossios et al., "Safety and efficacy of long-term statin treatment for cardiovascular events in patients with coronary heart disease and abnormal liver tests in the Greek Atorvastatin and Coronary Heart Disease Evaluation (GREACE) Study: a post-hoc analysis," The Lancet, vol. 376, no. 9756, pp. 1916-1922, 2010.

[21] U. A. Boelsterli, H. J. Zimmerman, and A. Kretz-Rommel, "Idiosyncratic liver toxicity of nonsteroidal antiinflammatory drugs: molecular mechanisms and pathology," Critical Reviews in Toxicology, vol. 25, no. 3, pp. 207-235, 1995.
[22] D. Bjorkman, "Nonsteroidal anti-inflammatory drug-associated toxicity of the liver, lower gastrointestinal tract, and esophagus," The American Journal of Medicine, vol. 105, no. 5, pp. 17S-21S, 1998.

[23] G. G. Gauglitz, J. Song, D. N. Herndon et al., "Characterization of the inflammatory response during acute and post-acute phases after severe burn," Shock, vol. 30, no. 5, pp. 503-507, 2008.

[24] L.-W. Chen, B. Hwang, W.-J. Chang, J.-S. Wang, J.-S. Chen, and C.-M. Hsu, "Inducible nitric oxide synthase inhibitor reverses exacerbating effects of hypertonic saline on lung injury in burn," Shock, vol. 22, no. 5, pp. 472-477, 2004.

[25] S. Ö. Iseri, Y. Ersoy, N. Gedik, F. Ercan, and I. Alican, "Protective role of adrenomedullin in burn-induced remote organ damage in the rat," Regulatory Peptides, vol. 146, no. 1-3, pp. 99-105, 2008.

[26] C. R. Baxter, "Management of fluid volume and electrolyte changes in the early postburn period," Geriatrics, vol. 30, no. 11, pp. 57-62, 1975.

[27] D. G. Greenhalgh and G. D. Warden, “The importance of intraabdominal pressure measurements in burned children," Journal of Trauma, vol. 36, no. 5, pp. 685-690, 1994.

[28] B. A. Latenser, A. Kowal-Vern, D. Kimball, A. Chakrin, and N. Dujovny, "A pilot study comparing percutaneous decompression with decompressive laparotomy for acute Abdominal Compartment Syndrome in thermal injury," Journal of Burn Care and Rehabilitation, vol. 23, no. 3, pp. 190-195, 2002.

[29] K. G. Hobson, K. M. Young, A. Ciraulo, T. L. Palmieri, and D. G. Greenhalgh, "Release of abdominal compartment syndrome improves survival in patients with burn injury," Journal of Trauma: Injury, Infection and Critical Care, vol. 53, no. 6, pp. 1129-1133, 2002.

[30] J. Oda, K. Yamashita, T. Inoue et al., "Resuscitation fluid volume and abdominal compartment syndrome in patients with major burns," Burns, vol. 32, no. 2, pp. 151-154, 2006.

[31] C. C. Finnerty, R. Przkora, D. N. Herndon, and M. G. Jeschke, "Cytokine expression profile over time in burned mice," Cytokine, vol. 45, no. 1, pp. 20-25, 2009.

[32] M. Kataranovski, Z. Magič, and N. Pejnovič, "Early inflammatory cytokine and acute phase protein response under the stress of thermal injury in rats," Physiological Research, vol. 48, no. 6, pp. 473-482, 1999.

[33] G. G. Gauglitz, J. Song, D. N. Herndon et al., "Characterization of the inflammatory response during acute and post-acute phases after severe burn," Shock, vol. 30, no. 5, pp. 503-507, 2008.

[34] J. L. Rodriguez, C. G. Miller, W. L. Garner et al., "Correlation of the local and systemic cytokine response with clinical outcome following thermal injury," Journal of Trauma, vol. 34, no. 5, pp. 684-696, 1993.

[35] M. H. G. Gehling, T. Luesebrink, P. J. Kulka, and M. Tryba, "The effective duration of analgesia after intrathecal morphine in patients without additional opioid analgesia: a randomized double-blind multicentre study on orthopaedic patients," European Journal of Anaesthesiology, vol. 26, no. 8, pp. 683-688, 2009.

[36] K. S. Luscombe, N. J. McDonnell, N. A. Muchatuta, M. J. Paech, and E. A. Nathan, "A randomised comparison of parecoxib versus placebo for pain management following minor day stay gynaecological surgery," Anaesthesia and Intensive Care, vol. 38, no. 1, pp. 141-148, 2010.

[37] R. Lloyd, S. Derry, R. A. Moore, and H. J. McQuay, "Intravenous or intramuscular parecoxib for acute postoperative pain in 
adults," Cochrane Database of Systematic Reviews, no. 2, Article ID CD004771, 2009.

[38] P. Piper and J. Vane, "The release of prostaglandins from lung and other tissues," Annals of the New York Academy of Sciences, vol. 180, pp. 363-385, 1971.

[39] A. Whelton, "Renal and related cardiovascular effects of conventional and COX-2-specific NSAIDs and non-NSAID analgesics," American Journal of Therapeutics, vol. 7, no. 2, pp. 63-74, 2000.

[40] R. C. Harris, J. A. McKanna, Y. Akai, H. R. Jacobson, R. N. Dubois, and M. D. Breyer, "Cyclooxygenase-2 is associated with the macula densa of rat kidney and increases with salt restriction," Journal of Clinical Investigation, vol. 94, no. 6, pp. 2504-2510, 1994.

[41] T. Mori, A. W. Cowley Jr., and S. Ito, "Molecular mechanisms and therapeutic strategies of chronic renal injury: physiological role of angiotensin II-induced oxidative stress in renal medulla," Journal of Pharmacological Sciences, vol. 100, no. 1, pp. 2-8, 2006.

[42] M. D. Murray and D. C. Brater, "Renal toxicity of the nonsteroidal anti-inflammatory drugs," Annual Review of Pharmacology and Toxicology, vol. 33, pp. 435-465, 1993.

[43] D. C. Brater, "Effects of nonsteroidal anti-inflammatory drugs on renal function: focus on cyclooxygenase -2-selective inhibition," American Journal of Medicine, vol. 107, no. 6, pp. 65S-70S, 1999.

[44] G. Arturson, "Pathophysiology of the burn wound and pharmacological treatment. The Rudi Hermans Lecture, 1995," Burns, vol. 22, no. 4, pp. 255-274, 1996.

[45] M. Bhatia and S. Moochhala, "Role of inflammatory mediators in the pathophysiology of acute respiratory distress syndrome," Journal of Pathology, vol. 202, no. 2, pp. 145-156, 2004.

[46] P. Dahiya, "Burns as a model of SIRS," Frontiers in Bioscience, vol. 14, no. 13, pp. 4962-4967, 2009. 


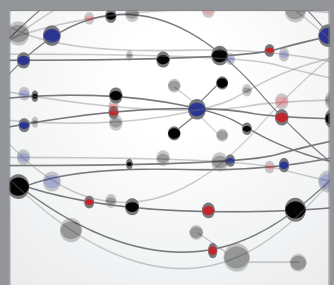

The Scientific World Journal
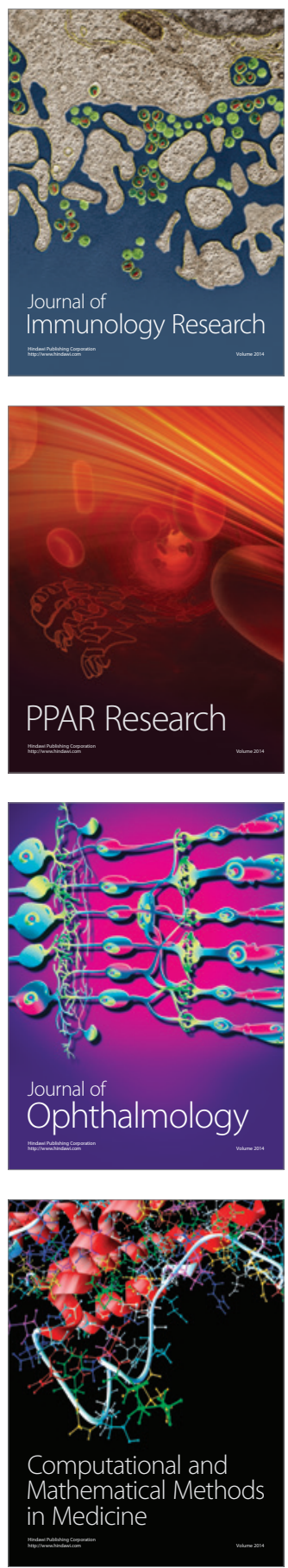

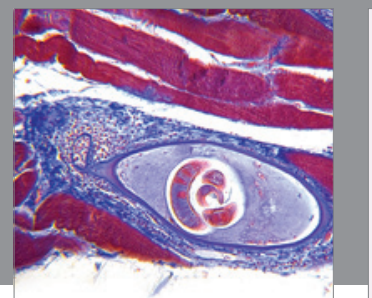

Gastroenterology

Research and Practice
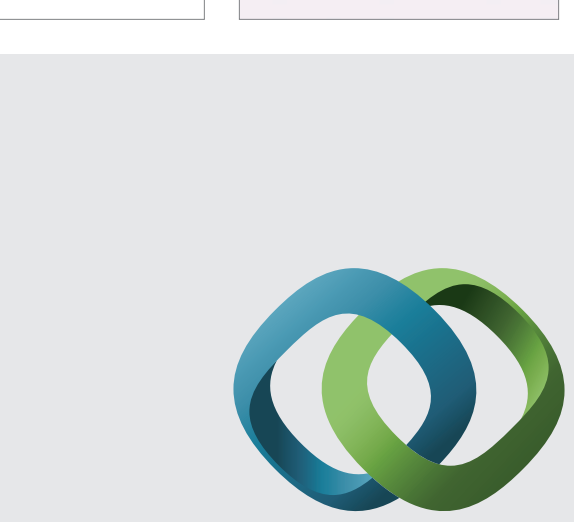

\section{Hindawi}

Submit your manuscripts at

http://www.hindawi.com
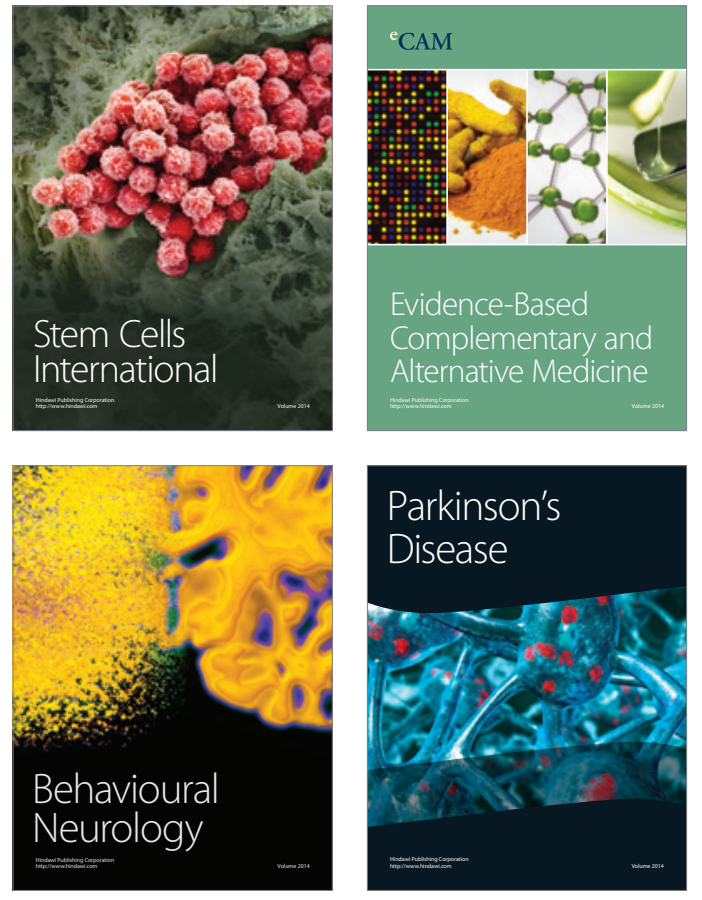
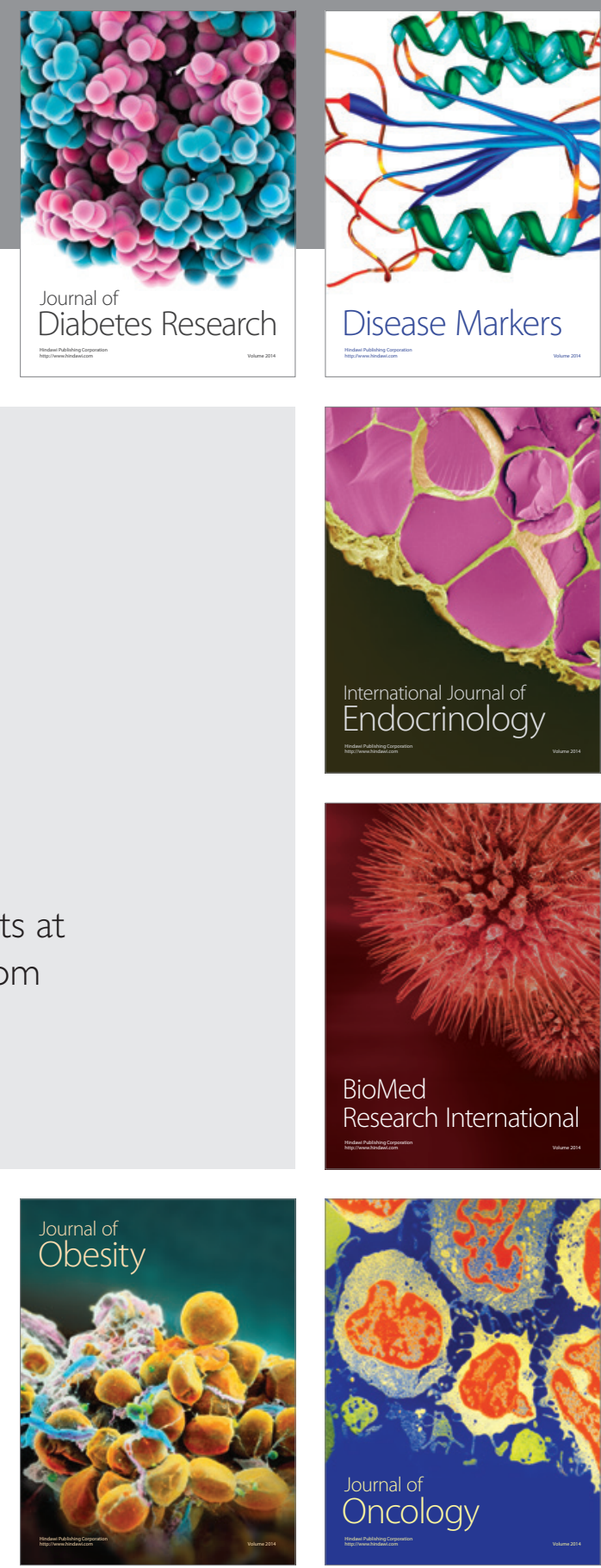

Disease Markers
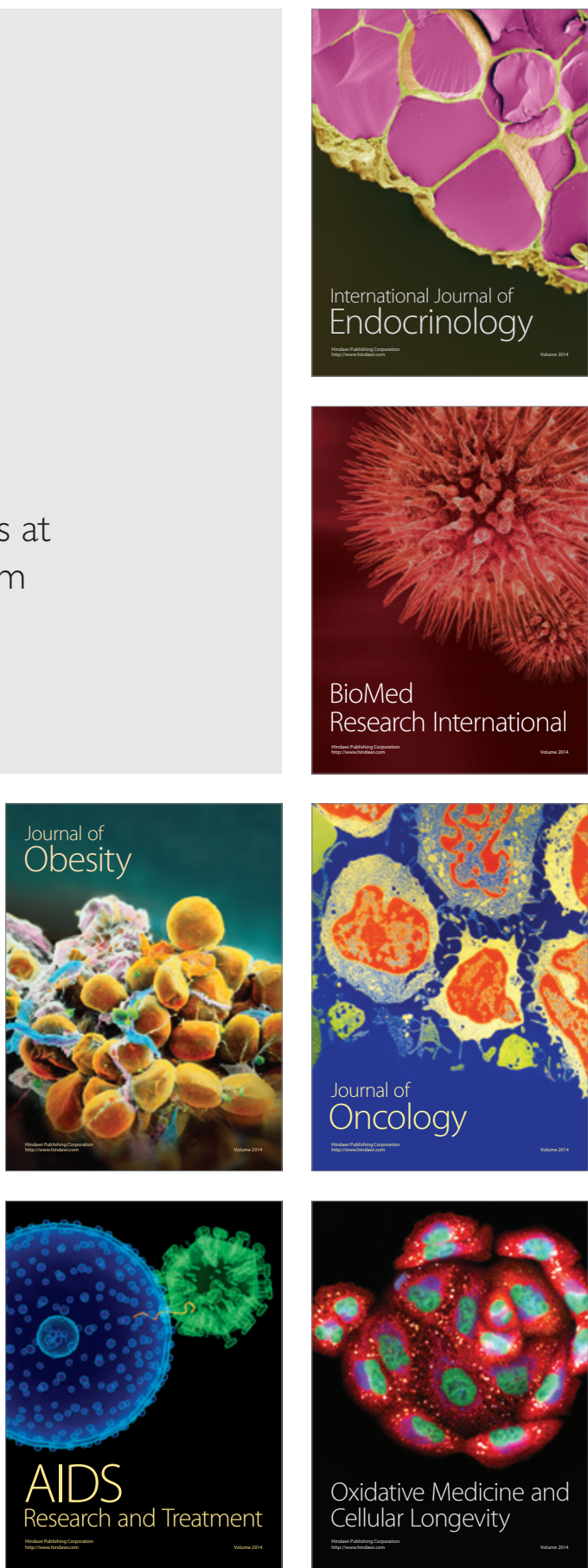